\title{
BMJ Open Effects of ischaemic postconditioning on outcomes of patients with ST-segment elevation myocardial infarction who underwent primary percutaneous coronary intervention: a meta-analysis
}

Zhenhua Xing, Liang Tang, Jiabing Huang, Xiaofan Peng, Xinqun Hu

To cite: Xing Z, Tang L, Huang J, et al. Effects of ischaemic postconditioning on outcomes of patients with STsegment elevation myocardial infarction who underwent primary percutaneous coronary intervention: a meta-analysis. BMJ Open 2019;9:e022509. doi:10.1136/ bmjopen-2018-022509

- Prepublication history and additional material for this paper are available online. To view these files, please visit the journal online (http://dx.doi org/10.1136/bmjopen-2018022509).

Received 22 February 2018 Revised 14 February 2019 Accepted 20 February 2019

Check for updates

(C) Author(s) (or their employer(s)) 2019. Re-use permitted under CC BY-NC. No commercial re-use. See rights and permissions. Published by BMJ.

Department of Cardiovascular Medicine, Second Xiangya Hospital, Changsha, Hunan, China

Correspondence to

Dr Xinqun $\mathrm{Hu}$;

huxinqun@csu.edu.cn

\section{ABSTRACT}

Objective The aim of this meta-analysis was to evaluate the effects of ischaemic postconditioning (IPC) therapy on hard clinical endpoints in ST-segment elevation myocardial infarction (STEMI) patients who underwent primary percutaneous coronary intervention (PPCl).

Design Systematic review and meta-analysis to evaluate the effects of IPC on the outcomes of patients with STEMI. Data sources PubMed, Embase and the Cochrane Library were systematically searched for relevant articles published prior to May 1, 2018.

Eligibility criteria for selecting studies Randomised trials comparing conventional $\mathrm{PPCl}$ to $\mathrm{PPCl}$ combined with IPC in STEMI patients were included. The primary endpoint was heart failure. Secondary endpoints were all-cause mortality and major adverse cardiac events (MACE), including cardiac death, heart failure and MI. The Cochrane Reviewer's Handbook 4.2 was used to assess the risk of bias.

Data extraction and synthesis Relevant data were extracted by two independent investigators. We derived pooled risk ratios (RRs) with random effects models. Sensitivity and subgroup analyses were performed. Results Ten studies that had enrolled 3137 patients were included. PPCI combined with IPC failed to reduce heart failure (RR: $0.88,95 \% \mathrm{Cl}: 0.61$ to $1.26, p=0.47$; absolute risk: $3.64 \%$ in the IPC group and $4.11 \%$ in the PPCI only group), all-cause mortality (RR: $0.94,95 \% \mathrm{Cl}: 0.69$ to 1.27 , $\mathrm{p}=0.68$; absolute risk: $5.07 \%$ in the IPC group and $5.27 \%$ in the PPCl onlygroup), MACE (RR: $1.05,95 \% \mathrm{Cl}: 0.83$ to 1.32, $p=0.69$; absolute risk: $9.37 \%$ in the IPC group and $8.93 \%$ in the PPCl only group), cardiac death (RR: 1.28 , $95 \% \mathrm{Cl}: 0.85$ to $1.93, \mathrm{p}=0.24$; absolute risk: $4.28 \%$ in the IPC group and $3.25 \%$ in the PPCI only group) and MI (RR: $1.08,95 \% \mathrm{Cl}: 0.38$ to $3.12, \mathrm{p}=0.88$; absolute risk: $3.61 \%$ in the IPC group and $3.44 \%$ in the PPCl only group). Conclusions IPC combined with $\mathrm{PPCl}$ does not reduce heart failure, MACE and all-cause mortality compared with traditional PPCl in patients with STEMI.

Trial registration number CRD42017063959

\section{BACKGROUND}

Primary percutaneous coronary intervention (PPCI) has been proven to be effective in patients with ST-segment elevation
Strengths and limitations of this study

- Unlike previous studies, we focused on clinical outcomes, such as heart failure or all-cause mortality.

- The recent DANAMI-3-iPOST study, which randomised 1234 patients with ST-segment elevation myocardial infarction (STEMI) to conventional primary percutaneous coronary intervention (PPCI) or $\mathrm{PPCl}$ with ischaemic postconditioning, was included, which may alter the conclusion regarding STEMI treatment.

- In order to give a solid conclusion, sensitivity and subgroup analyses were performed.

- A limitation of this meta-analysis is the inclusion of a relatively low number of patients.

myocardial infarction (STEMI) and has become a first-line therapy. ${ }^{1}$ Although PPCI is effective in restoring blood flow, ischaemic reperfusion injury is not inevitable. Reperfusion injury can also induce deleterious effects with a subsequent increase in infarct size, which accounts for up to $50 \%$ of the final size of a myocardial infarct. ${ }^{2}$ Both animal models of infarction and clinical proof-ofconcept studies have shown that reopening of the infarct-related artery, followed by repetitive brief interruptions of blood flow before sustained reperfusion, may protect the myocardium against reperfusion injury, which is evaluated using cardiac biomarkers, single-photon emission CT (SPECT), echocardiography and contrast-enhanced cardiac magnetic resonance. ${ }^{3-7}$ This strategy, known as ischaemic postconditioning (IPC), is safe and easy to perform without additional cost. $^{8}$ Related meta-analyses, using the above methods for evaluation, have also demonstrated that IPC can rescue cardiomyocytes. $^{9-11}$ However, whether improvements in these surrogate markers translate into 
improved clinical outcomes, such as reduction in heart failure and/or all-cause mortality, remains controversial. The recent DANAMI-3-iPOST study, which randomised 1234 patients with STEMI to conventional PPCI or PPCI with IPC did not provide evidence indicating that PPCI with IPC leads to better clinical outcomes compared with traditional PPCI. ${ }^{11}$

Given the confusion surrounding the different results related to IPC combined with PPCI, a meta-analysis was done to evaluate whether IPC has a beneficial effect on hard endpoints, such as heart failure, all-cause mortality and MACE, compared with traditional PPCI.

\section{METHODS}

\section{Patient and public involvement}

Qualitative patient data were the focus of this synthesis; however, patients and the public were not involved in the design of the study or analysis of the data.

\section{Search strategy and selection criteria}

This meta-analysis is reported in accordance to the Preferred Reporting Items for Systematic Reviews and Meta-Analyses statement. ${ }^{12}$ PubMed, Embase and Cochrane Library were systematically searched for relevant articles published before 1 May 2018. The terms 'IPC', 'PC', 'PCI', 'controlled trial (CT)', 'intervention study' and 'randomised CTs (RCTs)' were used to identify RCTs. MeSH, Emtree and keyword search terms were used in combination (online supplementary file). The results were limited to trials published in English. The reference lists of relevant studies and reviews, editorials and letters were manually searched to identify additional articles. Endnote (Thomson ISI ResearchSoft, Philadelphia, PA, USA) was used to manage relevant articles and remove duplicate articles.

\section{Study criteria, quality assessment and data extraction}

Studies were included in the meta-analysis when they met the following criteria: (1) the study design was a prospective randomised controlled clinical trial; (2) all patients with STEMI underwent PPCI treatment; (3) patients were randomly assigned to the PPCI in combination with the IPC group or the conventional PPCI group; (4) follow-up time was not less than 1 month and (5) relevant data were retrievable. When relevant data were missing, the authors were contacted by e-mail before excluding the references for inaccessibility of data.

The primary endpoint was heart failure. Secondary endpoints were all-cause mortality and major adverse cardiac events (MACE), including cardiac death, heart failure and MI. All clinical endpoints were evaluated according to per protocol definitions, at the longest available follow-up. Study quality was judged by evaluating trial procedures for random sequence generation (selection bias), allocation concealment (selection bias), blinding of participants and personnel (performance bias), blinding of outcome assessment (detection bias) and incomplete outcome data (attrition bias). The Cochrane Reviewer's Handbook 4.2 was used to assess the risk of bias.

\begin{tabular}{|c|c|c|c|c|c|c|c|c|c|}
\hline Study & $\begin{array}{l}\text { Patients } \\
\text { (IPC/C) }\end{array}$ & Country & $\begin{array}{l}\text { Age } \\
\text { (years, IPC/C) }\end{array}$ & $\begin{array}{l}\text { Male } \\
(\%, \text { IPC/C) }\end{array}$ & $\begin{array}{l}\text { Symptom } \\
\text { onset (hours) }\end{array}$ & $\begin{array}{l}\text { Protocol } \\
\text { (duration } \times \text { cycles) }\end{array}$ & $\begin{array}{l}\text { LAD } \\
(\%, \text { IPC/C) }\end{array}$ & $\begin{array}{l}\text { DES } \\
(\%, \text { IPC/C) }\end{array}$ & $\begin{array}{l}\text { Follow-up } \\
\text { (months) }\end{array}$ \\
\hline $\begin{array}{l}\text { Garcia } \\
\text { et al, } 2010^{15}\end{array}$ & $22 / 21$ & USA & $61 / 55$ & $86 / 76$ & $\leq 12$ & $30^{\prime \prime} / 30^{\prime \prime} \times 4$ & $36 / 24$ & - & 41 \\
\hline $\begin{array}{l}\text { Tarantini } \\
\text { et al, } 2012^{19}\end{array}$ & $39 / 39$ & Italy & $60 / 60$ & $85 / 85$ & $\leq 6$ & $60 " / 60^{\prime \prime} \times 4$ & $41 / 44$ & $0 / 2.6$ & 1 \\
\hline $\begin{array}{l}\text { Dong } \\
\text { et } a l, 2013^{20}\end{array}$ & $32 / 30$ & China & $70 / 68$ & $63 / 73$ & $\leq 12$ & $30^{\prime \prime} / 30^{\prime \prime} \times 3$ & $57 / 43$ & - & 1 \\
\hline $\begin{array}{l}\text { Limalanathan } \\
\text { et al, } 2014^{18}\end{array}$ & $136 / 136$ & Norway & $61 / 60$ & $84 / 80$ & $\leq 6$ & $60 " / 60^{\prime \prime} \times 4$ & $46 / 51$ & $29 / 29$ & 4 \\
\hline $\begin{array}{l}\text { Eitel } \\
\text { et al, } 2015^{13}\end{array}$ & $232 / 232$ & Germany & $62 / 65$ & $76 / 71$ & $\leq 12$ & $30^{\prime \prime} / 30^{\prime \prime} \times 4$ & $42 / 51$ & - & 6 \\
\hline $\begin{array}{l}\text { Luz } \\
\text { et al, } 2015^{17}\end{array}$ & $43 / 44$ & Portugal & $57 / 58$ & $88 / 82$ & $\leq 12$ & $60^{\prime \prime} / 60^{\prime \prime} \times 4$ & $47 / 43$ & $65 / 71$ & 14 \\
\hline $\begin{array}{l}\text { Engstrøm } \\
\text { et al, } 2017^{8}\end{array}$ & $617 / 617$ & Denmark & $63 / 62$ & $80 / 79$ & $\leq 12$ & $30 " / 30^{\prime \prime} \times 4$ & $43 / 40$ & $93 / 93$ & 38 \\
\hline
\end{tabular}

C, control group (primary percutaneous coronary intervention only); DES, drug-eluted stent; IPC, ischaemic postconditioning group; LAD, leftdescending anterior branch. 


\begin{tabular}{|c|c|c|c|c|c|}
\hline \multirow[b]{2}{*}{ Study or Subgroup } & \multicolumn{2}{|l|}{ IPC } & \multicolumn{2}{|c|}{ Traditional treatment } & \multirow[b]{2}{*}{ Weigh } \\
\hline & Events & Total & Events & Total & \\
\hline Garcia 2010 & 2 & 22 & 4 & 21 & \\
\hline Freixa 2012 & 2 & 39 & 2 & 40 & \\
\hline Tarantini 2012 & 2 & 39 & 0 & 39 & \\
\hline Dong 2013 & 2 & 32 & 0 & 30 & \\
\hline Limalanathan 2014 & 2 & 136 & 5 & 136 & 5.0 \\
\hline Eitel 2015 & 6 & 232 & 13 & 232 & 14.5 \\
\hline Luz 2015 & 0 & 43 & 0 & 44 & \\
\hline Hahn 2015 & 9 & 350 & 8 & 350 & 14.8 \\
\hline Engstrøm 2017 & 30 & 617 & 30 & 617 & 53.9 \\
\hline Total $(95 \% \mathrm{Cl})$ & & 1510 & & 1509 & 100. \\
\hline Total events & 55 & & 62 & & \\
\hline Heterogeneity: $\mathrm{Tau}^{2}$ & .00; $\mathrm{Chi}^{2}$ & 0.28 & df $=7(P=0$ & $2=0 \%$ & \\
\hline Test for overall effec & $=0.72(\mathrm{~F}$ & $=0.4$ & & & \\
\hline
\end{tabular}

Risk Ratio

M-H. Random. 95\% Cl Year

$0.48[0.10,2.34] 2010$

$1.03[0.15,6.92] 2012$

$5.00[0.25,100.89] 2012$

$4.70[0.23,94.01] 2013$

$0.40[0.08,2.03] 2014$

$0.46[0.18,1.19] 2015$

Not estimable 2015

$1.13[0.44,2.88] 2015$

$1.00[0.61,1.64] 2017$

$0.88[0.61,1.26]$
Risk Ratio M-H, Random, 95\% Cl

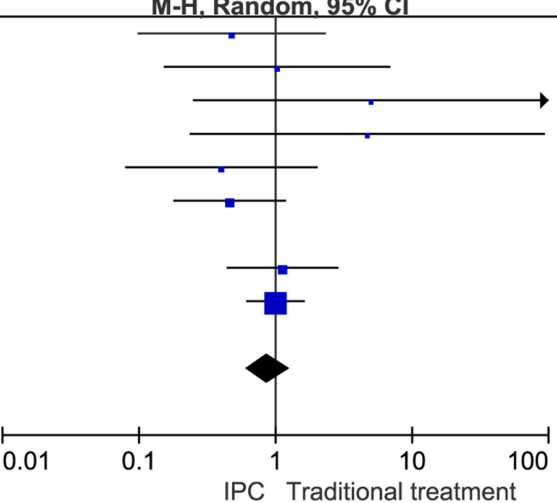

Figure 1 Effect of PPCl with IPC versus PPCl only on heart failure in STEMI patients undergoing PPCI. IPC, ischaemic postconditioning group; PPCl, primary percutaneous coronary intervention; STEMI, ST-segment elevation myocardial infarction.

Relevant data were extracted by two independent investigators (XP and JH). Disagreements were resolved by consensus or a third investigator $(\mathrm{XH})$. The following data were abstracted from the selected articles: first author, publication date, study design, onset of symptoms, characteristics of included participants, total number of IPC and conventional groups, events of the IPC and conventional groups, stent type and follow-up time.

\section{Data analysis}

Meta-analysis was performed to calculate the risk ratio (RR) and 95\% CI. Pooled RRs were computed as the Mantel-Haenszel-weighted average of the RRs for all included studies. Because the true treatment effect of various IPC protocols may have varied among the included trials, the random effects model was used in the analysis. Statistical heterogeneity among the trial-specific RRs was checked and quantified by the $\mathrm{I}^{2}$ statistic, and a $\mathrm{p}$ value $\leq 0.05$ was considered statistically significant. We performed sensitivity analysis to assess the contribution of each study to the pooled estimation by excluding one trial at a time and recalculating the pooled RR estimation for the remaining studies. Subgroup analyses were conducted in terms of time of symptom onset, IPC protocols and antiplatelet therapies. Data analysis was performed on an intention-to-treat basis. All analyses were performed using Review Manager Software (Review Manager [RevMan] [Computer program]. V.5.3. Copenhagen: The Nordic Cochrane Centre, The Cochrane Collaboration, 2014.).

\section{Outcomes}

Search results and bias assessment

Online supplementary figure 1 shows that the combined search strategy identified 273 potential relevant manuscripts, from which 33 studies were retrieved for more detailed assessment (detailed search strategies for PubMed is shown in the complementary file). A total of 10 RCTs, involving 3137 patients, are included in this meta-analysis. ${ }^{7813-20}$ The Cochrane Reviewer's Handbook 4.2 was used to assess the risk of bias (online supplementary figure 2). No high-risk studies were identified and six studies had a low risk of bias.

The main features of the 10 included RCTs and the baseline clinical characteristics of the patients are presented in table 1 . In the 10 trials, 1569 patients (50\%) were randomly assigned to PPCI with IPC. The mean age of the trial patients was 61 years and $78 \%$ of the patients were male. The IPC protocols (cycles $\times$ ischaemia/reperfusion in seconds) varied between studies and were as follows: $30^{\prime \prime} / 30^{\prime \prime} \times 4$ in four studies, $60^{\prime \prime} / 60^{\prime \prime} \times 4$ in five studies and

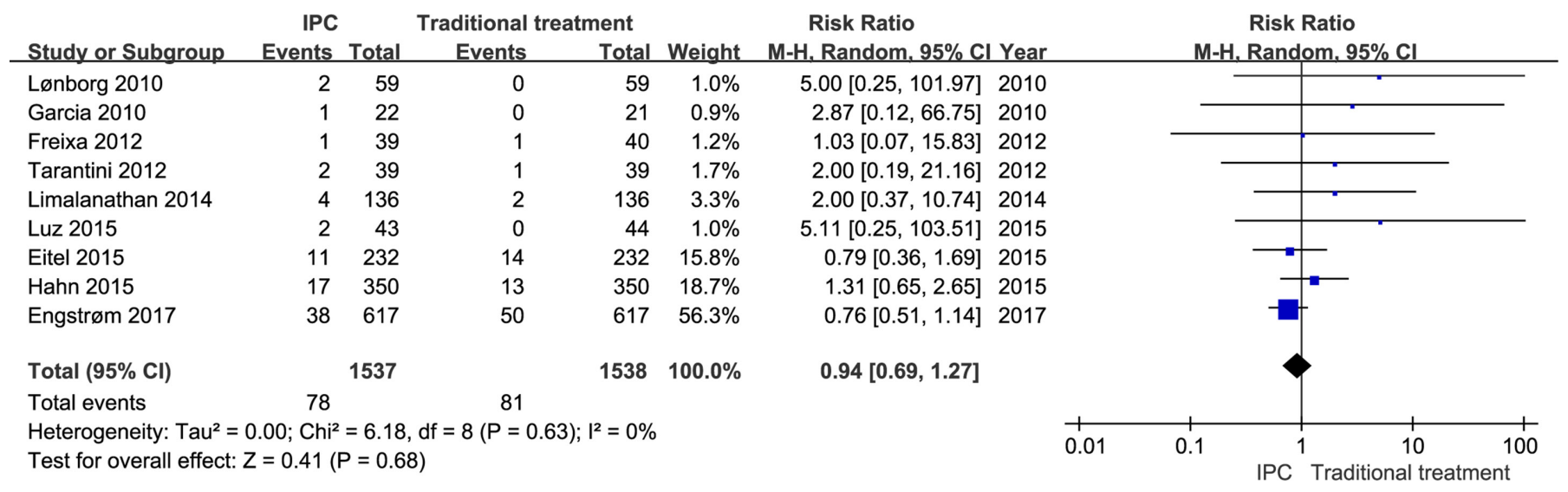

Figure 2 Effect of PPCI with IPC versus PPCI only on all-cause mortality in STEMI patients undergoing PPCI. IPC, ischaemic postconditioning group; PPCl, primary percutaneous coronary intervention; STEMI, ST-segment elevation myocardial infarction. 


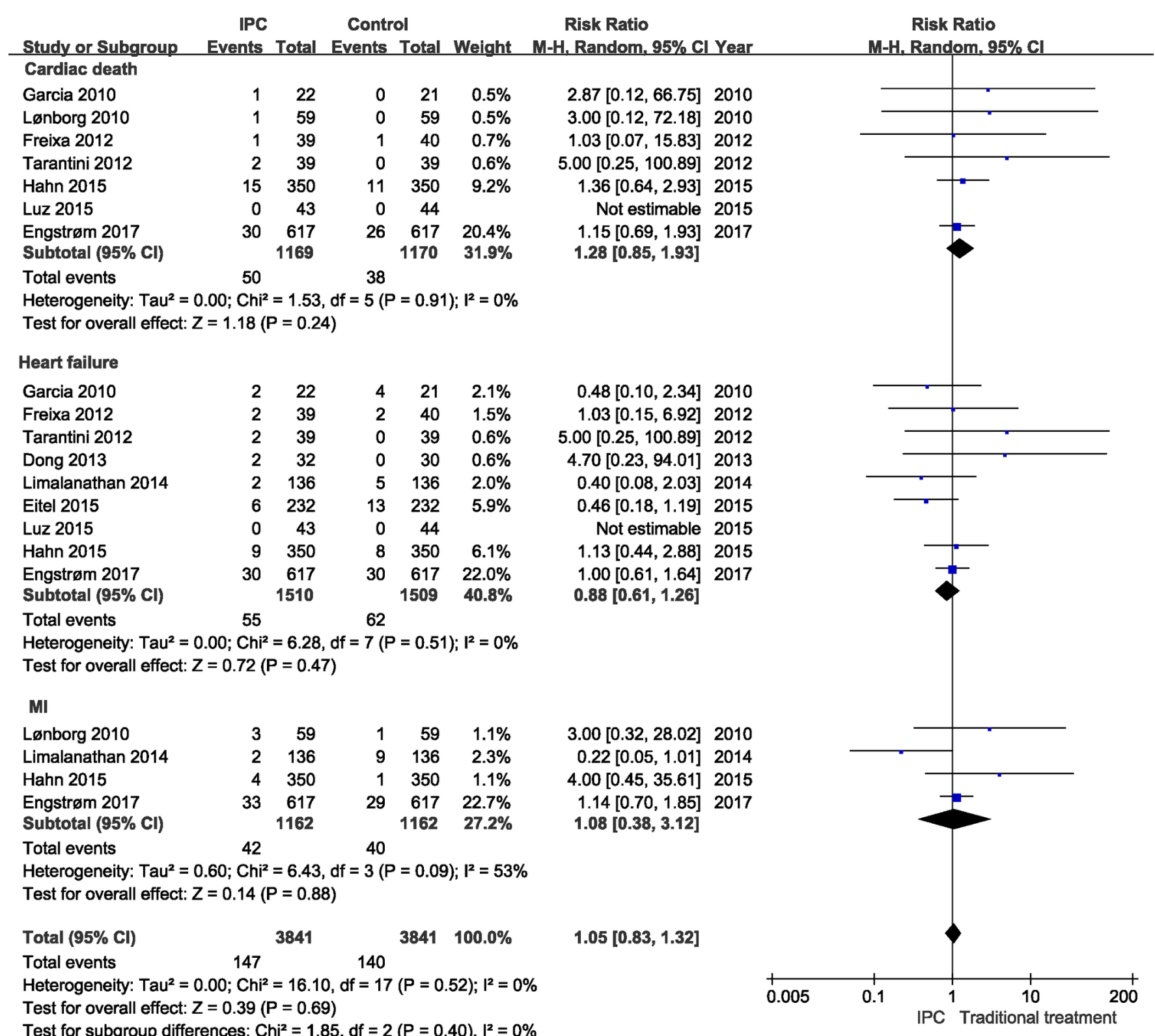

Figure 3 Effect of PPCl with IPC versus PPCI only on MACE in STEMI patients undergoing PPCI. IPC, ischaemic postconditioning group; MACE, major adverse cardiac events; PPCl, primary percutaneous coronary intervention; STEMI, STsegment elevation myocardial infarction.

$30^{\prime \prime} / 30^{\prime \prime} \times 3$ in one study. Follow-up among trials varied from 1 month to 41 months. The time of symptom onset varied between studies from 6 hours in two studies to 12 hours in eight studies.

\section{Primary endpoint: heart failure}

When the data were pooled, the RR for heart failure was 0.88 (95\% CI: 0.61 to $1.26, p=0.47$; absolute risk: $3.64 \%$ in the IPC group and $4.11 \%$ in the PPCI only group) in the random effects model (figure 1 ). No evident statistical heterogeneity among studies was observed $\left(\mathrm{I}^{2}=0, \mathrm{p}=0.51\right)$. IPC during PPCI did not reduce heart failure compared with traditional PPCI.

\section{Secondary endpoints: all-cause mortality and MACE}

The pooled data showed that IPC did not reduce all-cause mortality compared with traditional PPCI (RR:
0.94, $95 \%$ CI: 0.69 to $1.27, \mathrm{p}=0.68$; absolute risk: $5.07 \%$ in the IPC group and $5.27 \%$ in the PPCI only group, figure 2). No evident statistical heterogeneity among studies was observed $\left(\mathrm{I}^{2}=0, \mathrm{p}=0.63\right)$. Furthermore, IPC did not reduce cardiac death (RR: $1.28,95 \% \mathrm{CI}$ : 0.85 to $1.93, \mathrm{p}=0.24$; absolute risk: $4.28 \%$ in the IPC group and $3.25 \%$ in the PPCI only group), MI (RR: 1.08 , 95\% CI: 0.38 to $3.12, p=0.88$; absolute risk: $3.61 \%$ in the IPC group and $3.44 \%$ in the PPCI only group) and heart failure (RR: $0.85,95 \%$ CI: 0.59 to $1.23, p=0.40$; absolute risk: $3.64 \%$ in the IPC group and $4.11 \%$ in the PPCI only group). When all events (MACE) were considered, IPC during PPCI provided no net benefit of IPC during PPCI (RR: $1.05,95 \%$ CI: 0.83 to $1.32, p=0.69$; absolute risk: $9.37 \%$ in the IPC group and $8.93 \%$ in the PPCI only group, figure 3 ). 
Table 2 Subgroup analysis

\begin{tabular}{|c|c|c|c|c|}
\hline & Cardiac death & Heart failure & MI & All-cause mortality \\
\hline \multicolumn{5}{|l|}{ Symptom onset } \\
\hline$\leq 6$ hours & 5.00 (0.25 to 101$)$ & 1.02 (0.09 to 11.5$)$ & 0.22 (0.05 to 1.01$)$ & 2.00 (0.51 to 7.86$)$ \\
\hline \multicolumn{5}{|l|}{ Protocol } \\
\hline $30^{\prime \prime} / 30^{\prime \prime} \times 4$ & 1.21 (0.73 to 1.99$)$ & 0.76 (0.45 to 1.29$)$ & $1.19(0.74$ to 1.91$)$ & 0.80 (0.56 to 1.14$)$ \\
\hline \multicolumn{5}{|l|}{ Follow-up } \\
\hline$\leq 12$ months & 1.49 (0.74 to 2.99$)$ & 0.81 (0.44 to 1.47$)$ & 1.20 (0.16 to 8.81$)$ & $1.16(0.73$ to 1.87$)$ \\
\hline$>12$ months & 1.18 (0.71 to 1.96$)$ & 0.94 (0.58 to 1.50$)$ & $1.14(0.70$ to 1.85$)$ & $0.88(0.45$ to 1.71$)$ \\
\hline \multicolumn{5}{|l|}{ Analysis model } \\
\hline Clopidogrel & $1.28(0.85$ to 1.93$)$ & 0.98 (0.66 to 1.45$)$ & 1.08 (0.38 to 3.12$)$ & 0.97 (0.69 to 1.35$)$ \\
\hline GPIIb/IIla inhibitors & $1.23(0.81$ to 1.88$)$ & 0.84 (0.56 to 1.27$)$ & 1.08 (0.38 to 3.12$)$ & 0.93 (0.67 to 1.30$)$ \\
\hline Bivalirudin & 1.44 (0.70 to 2.94$)$ & 0.98 (0.47 to 2.03$)$ & $0.84(0.77$ to 14.24$)$ & 1.48 (0.81 to 2.69$)$ \\
\hline
\end{tabular}

MI, myocardial infarction.

\section{Sensitivity analysis and potential sources of heterogeneity}

Sensitivity testing was performed by excluding each included study, one at a time, and recalculating the overall effects. The direction of the overall effects, in terms of heart failure, MI, cardiac death and all-cause mortality, were not influenced no matter which study was excluded (online supplementary table 1 ).

There were very little heterogeneities between studies with regard to the observed effects on all-cause mortality $\left(I^{2}=0, p=0.63\right)$ and cardiac death $\left(I^{2}=0, p=0.91\right)$. However, moderate between-study heterogeneity was identified in the case of MI $\left(\mathrm{I}^{2}=53 \%, \mathrm{p}=0.09\right)$. MI heterogeneity was mainly caused by the Limalanathan 2014 study. When this study was excluded, no heterogeneity was observed $\left(\mathrm{I}^{2}=0 \%, \mathrm{p}=0.40\right)$ and the conclusions were still consistent with the previous analysis. Subgroup analysis did not identify any baseline risk factor, such as symptom onset, duration of follow-up or antiplatelet therapies, as a modifier of the relationship between IPC and clinical endpoints (table 2).

\section{DISCUSSION}

The current meta-analysis of 10 RCTs, including 3137 patients with STEMI undergoing PPCI, showed that no reduction in heart failure, all-cause mortality or MACE when comparing PPCI in combination with IPC to traditional PPCI over a mean follow-up of 20 months. Similarly, no improvement in clinical outcomes was shown in the subgroup analysis.

IPC was first introduced by Zhao et al in $2003 .{ }^{21}$ Subsequent clinical trials and meta-analyses found a salutary effect of IPC on infarct size as evaluated by CK, CK-MB, troponin, SPECT and cardiac function based on the left ventricular ejection fraction. ${ }^{3-5}$ However, opposite results have also been reported. ${ }^{8}{ }^{16-19}$ The DANAMI-3-iPOST trial, which is the largest study to date, showed that IPC did not reduce infarct size. ${ }^{8}$ Furthermore, whether surrogate endpoints, such as infarct size, myocardial salvage and resolution of ST-segment elevation, translate into hard endpoints, such as heart failure, all-cause mortality or MACE, remains a point of debate. Unlike the above surrogate endpoints, heart failure, all-cause mortality and MACE are what are generally considered to be most important by both clinics and patients.

Previous meta-analyses mainly focused on cardiac biomarkers, cardiac imaging and cardiac function; however, clinical outcomes are also very consequential. In the current meta-analysis, IPC was not shown to improve clinical outcomes, though several factors may influence its effectiveness. A meta-analysis of 19 RCTs concluded that cardioprotection, as evaluated by cardiac enzyme leakage, infarct size and left ventricular function, is more likely in patients with LAD artery involvement because of a greater myocardial area is at risk. ${ }^{9}$ Zhou et al performed a meta-analysis of $10 \mathrm{RCTs}$ and found that the effects of cardiac protection were more pronounced among young and male patients and those who received direct stenting. ${ }^{10}$ The IPC protocol is also an important factor in determining the IPC efficacy. IPC may cause myocardial ischaemia and expand the infarct area. Several trials chose four cycles of 1 min of reperfusion followed by $1 \mathrm{~min}$ of reocclusion. However, other trials selected four cycles of $30 \mathrm{~s}$ reperfusion followed by $30 \mathrm{~s}$ low-pressure balloon occlusion. However, the subgroup analyses in the 
current study found no differences in the effectiveness of IPC when comparing different protocols.

Time of symptom onset, which is an independent predictor of MACE in patients with STEMI undergoing PPCI, may have influenced the results of these trials. However, subgroup analysis in this study did not detect differences between trials related to the time of symptom onset. The key reason is that IPC might have no effect on cardioprotection; thus, the results of the subgroup analysis in this study were neutral. Furthermore, the sample size of the studies may have been too small to detect minor beneficial effects. Several confounding factors, such as baseline characteristics of patients, coexisting diseases, medications and IPC strategies used, may have influenced the cardioprotective benefits of IPC. With the use of novel antiplatelet and lipid-lowering agents and timely PPCI, the outcome of STEMI has significantly improved. The decreasing mortality rate also makes it harder to demonstrate minor benefits of using additional therapy.

\section{LIMITATIONS}

This study has several limitations. First, although no apparent heterogeneity in statistical analysis was observed, variations in the methodology among studies, such as different risk profiles of the included patients, IPC strategies and follow-up times, were observed. However, according to the meta-regression and subgroup analyses performed in this study, the above heterogeneities should not have affected the conclusion. In addition, the conclusion was based on the random effects model, which accounts for a certain degree of heterogeneity. Second, because of low incidence of adverse events, such as heart failure, the sample size is relatively small. Nonetheless, this meta-analysis is the largest population-based analysis of IPC. Additional RCTs are necessary to evaluate longterm clinical outcomes.

\section{CONCLUSIONS}

This meta-analysis suggests that the use of IPC in STEMI patients undergoing PPCI does not reduce the incidence of heart failure, MACE and all-cause mortality compared with traditional PPCI.

Contributors $\mathrm{XH}$ and $\mathrm{ZX}$ designed the study and provided methodological expertise in systematic reviews and searching strategies. ZX and LT drafted the manuscript. $\mathrm{JH}$ and XP searched the databases and constructed the tables. All authors have read, provided critical feedback and approved the final manuscript.

Funding This work was supported by a grant from the 2015 Yu-Ying Plan of the Central South University (Grant No. 502034007).

Competing interests None declared.

Patient consent for publication Not required.

Provenance and peer review Not commissioned; externally peer reviewed.

Data sharing statement All data generated and research materials used during this systematic review and meta-analysis are available from the corresponding author on reasonable request.
Open access This is an open access article distributed in accordance with the Creative Commons Attribution Non Commercial (CC BY-NC 4.0) license, which permits others to distribute, remix, adapt, build upon this work non-commercially, and license their derivative works on different terms, provided the original work is properly cited, appropriate credit is given, any changes made indicated, and the use is non-commercial. See: http://creativecommons.org/licenses/by-nc/4.0/.

\section{REFERENCES}

1. Levine GN, Bates ER, Blankenship JC, et al. 2015 ACC/AHA SCAI Focused Update on Primary Percutaneous Coronary Intervention for Patients With ST-Elevation Myocardial Infarction: An Update of the 2011 ACCF/AHA/SCAI Guideline for Percutaneous Coronary Intervention and the 2013 ACCF/AHA Guideline for the Management of ST-Elevation Myocardial Infarction. J Am Coll Cardiol 2016;67:1235-50.

2. Yellon DM, Hausenloy DJ. Myocardial reperfusion injury. N Engl J Med 2007;357:1121-35.

3. Ma X, Zhang X, Li C, et al. Effect of postconditioning on coronary blood flow velocity and endothelial function and LV recovery after myocardial infarction. J Interv Cardiol 2006;19:367-75.

4. Laskey WK, Yoon S, Calzada N, et al. Concordant improvements in coronary flow reserve and ST-segment resolution during percutaneous coronary intervention for acute myocardial infarction: a benefit of postconditioning. Catheter Cardiovasc Interv 2008;72:212-20.

5. Yang XC, Liu Y, Wang LF, et al. Reduction in myocardial infarct size by postconditioning in patients after percutaneous coronary intervention. J Invasive Cardiol 2007;19:424-30.

6. Thibault H, Piot C, Staat P, et al. Long-term benefit of postconditioning. Circulation 2008;117:1037-44.

7. Lønborg J, Kelbaek H, Vejlstrup N, et al. Cardioprotective effects of ischemic postconditioning in patients treated with primary percutaneous coronary intervention, evaluated by magnetic resonance. Circ Cardiovasc Interv 2010;3:34-41.

8. Engstrøm T, Kelbæk H, Helqvist $\mathrm{S}$, et al. Effect of Ischemic Postconditioning During Primary Percutaneous Coronary Intervention for Patients With ST-Segment Elevation Myocardial Infarction: A Randomized Clinical Trial. JAMA Cardiol 2017;2:490.

9. Khan AR, Binabdulhak AA, Alastal $Y$, et al. Cardioprotective role of ischemic postconditioning in acute myocardial infarction: a systematic review and meta-analysis. Am Heart J 2014;168:512-21.

10. Zhou $C$, Yao Y, Zheng Z, et al. Stenting technique, gender, and age are associated with cardioprotection by ischaemic postconditioning in primary coronary intervention: a systematic review of 10 randomized trials. Eur Heart J 2012;33:3070-7.

11. Liu BS, Xu F, Wang JL, et al. The cardioprotection of ischemic postconditioning in patients with acute ST-segment elevation myocardial infarction undergoing primary percutaneous coronary intervention. Int J Cardiol 2015;178:181-3.

12. Liberati A, Altman DG, Tetzlaff $\mathrm{J}$, et al. The PRISMA statement for reporting systematic reviews and meta-analyses of studies that evaluate healthcare interventions: explanation and elaboration. BMJ 2009;339:b2700.

13. Eitel I, Stiermaier T, Rommel KP, et al. Cardioprotection by combined intrahospital remote ischaemic perconditioning and postconditioning in ST-elevation myocardial infarction: the randomized LIPSIA CONDITIONING trial. Eur Heart J 2015;36:3049-57.

14. Freixa X, Bellera N, Ortiz-Pérez JT, et al. Ischaemic postconditioning revisited: lack of effects on infarct size following primary percutaneous coronary intervention. Eur Heart J 2012;33:103-12.

15. Garcia S, Henry TD, Wang YL, et al. Long-term follow-up of patients undergoing postconditioning during ST-elevation myocardial infarction. J Cardiovasc Trans/ Res 2011;4:92-8.

16. Hahn JY, Yu CW, Park HS, et al. Long-term effects of ischemic postconditioning on clinical outcomes: 1-year follow-up of the POST randomized trial. Am Heart J 2015;169:639-46.

17. Luz A, Santos M, Magalhães R, et al. Lack of Benefit of Ischemic Postconditioning After Routine Thrombus Aspiration During Reperfusion: Immediate and Midterm Results. J Cardiovasc Pharmacol Ther 2015;20:523-31.

18. Limalanathan $\mathrm{S}$, Andersen GØ, Kløw NE, et al. Effect of ischemic postconditioning on infarct size in patients with ST-elevation myocardial infarction treated by primary $\mathrm{PCI}$ results of the POSTEMI (POstconditioning in ST-Elevation Myocardial Infarction) randomized trial. J Am Heart Assoc 2014;3:e000679.

19. Tarantini G, Favaretto E, Marra MP, et al. Postconditioning during coronary angioplasty in acute myocardial infarction: the POST-AMI trial. Int J Cardiol 2012;162:33-8. 
20. Dong M, Mu N, Guo F, et al. The beneficial effects of postconditioning on no-reflow phenomenon after percutaneous coronary intervention in patients with ST-elevation acute myocardial infarction. J Thromb Thrombolysis 2014;38:208-14.
21. Zhao ZQ, Corvera JS, Halkos ME, et al. Inhibition of myocardial injury by ischemic postconditioning during reperfusion: comparison with ischemic preconditioning. Am J Physiol Heart Circ Physiol 2003;285:H579-88. 
Correction: Effects of ischaemic postconditioning on outcomes of patients with ST-segment elevation myocardial infarction who underwent primary percutaneous coronary intervention: a meta-analysis

Xing Z, Tang L, Huang J, et al. Effects of ischaemic postconditioning on outcomes of patients with ST-segment elevation myocardial infarction who underwent primary percutaneous coronary intervention: a meta-analysis. BMJ Open 2019;9:e022509. doi: 10.1136/bmjopen-2018-022509

This article was previously published with an error.

Central South University was omitted in the author affiliations. The correct affiliation of authors is:

Department of Cardiovascular Medicine, Second Xiangya Hospital, Central South University, Changsha, Hunan, China

Open access This is an open access article distributed in accordance with the Creative Commons Attribution Non Commercial (CC BY-NC 4.0) license, which permits others to distribute, remix, adapt, build upon this work non-commercially, and license their derivative works on different terms, provided the original work is properly cited, appropriate credit is given, any changes made indicated, and the use is non-commercial. See: http://creativecommons.org/licenses/by-nc/4.0/.

(C) Author(s) (or their employer(s)) 2019. Re-use permitted under CC BY-NC. No commercial re-use. See rights and permissions. Published by BMJ.

BMJ Open 2019;9:e022509corr1. doi:10.1136/bmjopen-2018-022509corr1

Check for updates 